Journal of Universal Language 2

March 2001, 3-14

\title{
The Need for "Unish", a Universal Language and the Principles of its Development
}

\author{
Myung-gun Choo \\ Sejong Institution
}

\begin{abstract}
Although a single linguistic medium for international communication is desperately needed, as globalization continues apace, the role of English as an international language has been eroded because of its irregularity of pronunciation and grammar. Therefore, the purpose of this paper is to ensure the need for a new universal language, Unish and to illustrate seven principles of its development: commonness, shortness, diversity, distinctiveness. simplicity, cultural association, and compounding. Given this, Unish, made up by adopting the advantages of natural languages, is characterized by little inflections and no gender distinctions. Moreover, this paper discusses how to disseminate Unish in effective ways.
\end{abstract}

\section{Introduction}

As civilization continues to progress, the world is truly becoming a global village with increased interdependence between nations. As recently as two hundred years ago, the only mode of overland travel was by horses and horse-drawn carriages. A mere two centuries later, jet planes whisk people across the globe at roughly 1,000 
kilometers per hour, which implies that conceptually the world has shrunk to one hundredth of its former size. Furthermore, no matter how powerful and wealthy a nation might be, in today's world it cannot survive without international trade. This eventually led to the evolution of organizations which transcend economic barriers between countries, and the world is becoming a global community sharing a common future.

In the areas of information and communication, the Internet is bringing the world together at an explosive speed as even people in remote comers of the globe have the means to send and receive a huge amount of information instantly. In the realm of politics, various transnational and supranational organizations play major roles in bringing the world into one vast political community.

Languages, however, remain as the most difficult obstacle the world must overcome in building a genuinely global community. We are forced to spend an exorbitant amount of time and money learning other languages just to be able to communicate with our foreign neighbors. Minor misunderstandings arise all the time due to inefficient communication, and sometimes these can lead to serious disputes among the parties involved. Additionally, as the degree of economic, scientific, and technological progress has more or less been leveled, the number of languages in need of translation has grown astronomically. While computers may be able to perform automatic translations, it is on an extremely limited scale, and for faithful and accurate translations, a new form of universal language that can act as an intervening medium is sorely needed.

\section{Historical Review of Artificial Languages}

European countries had an early recognition that they needed an international language to overcome the language barriers created by the various languages employed there. The history of an artificial language goes back to Coine Greek of the 4th century B.C. when Alexander the Great unified areas in today's Middle East. There have been innumerable attempts at an international language since 
then; they were mostly based on European languages. This was because a relatively small Europe was jammed with many countries experiencing close interactions, and their similar languages made it easy for them to develop a common universal language. Latin played such an international role for centuries in Europe, and with the emergence of France as a strong power in the seventeenth century, French became the language of diplomacy (Large 1985). In later years, however, when the advancement in publishing technologies and trade along with the religious reforms made each and every country in Europe thrive as independent and powerful nations; the adoption of one particular natural language as a universal language was out of the question. This separateness helped create the need for a common language (Glossop 1988). Francis Bacon and Gottfried Wilhelm von Leibnitz also proposed artificial languages as an equal medium of communication. The most successful of all the attempts to create a lingua franca have been Esperanto and Ido. However, they have been unsatisfactory because they are largely based on Latin or Eastern European languages.

\section{Limitations of English as a Universal Language}

As globalization continues apace, the demand for an international medium of communication has today become even more crucial. Not a few problems arise when one particular language like English is adopted as a universal language (Comrie 1999). The people in English- speaking countries would be automatically vaulted into a privileged position; it is not fair for non-English speakers. For them, English is not easy to learn due to its irregularity of grammar and pronunciation, even though they put a huge amount of time and energy into it (Diamond 1999). Non-English speakers know well that when English is adopted as a universal language, they are likely to be reduced to the status of second class global citizens. That is why they are hoping for the emergence of an artificial universal language in the near future. 
Supporters of English as a universal language usually base their argument on the belief that the United States wields political and economic dominance over the world. However, their claim places in a privileged position English-speaking countries which comprise no more than a scant 5 percent of world population. It is not surprising that their assertion will not be readily accepted by non-English speakers. In the past, France ruled England for centuries; it couldn't get rid of English. Likewise, no matter how strong the Anglo-American power might be, France cannot be forced to use English. Given the fact that French Canadians have continued to struggle for their independence for over two hundred years, we can realize the serious consequences of social conflicts created as a result of language and political disparities. It is close to impossible to imagine that countries of large population and strong national power like Germany, Russia and China will accept English as a universal language.

As mentioned above, many European countries have long recognized the necessity of a universal language, even though they are all on speaking terms with English and share the common roots of European languages (Large 1996). They reject the idea of English as a universal language because the criterion of English-speaking ability will determine the income and class of people although they are not indiscriminately against English. What they want from a common language is fairness and ease of acquisition (Suzanne 1988).

\section{Necessity of a Universal Language}

Our ancestors lived together in and around Equatorial Africa. The end of the Ice Age made travel possible, and in groups they scattered across the Temperate Zone. Settling into different areas, each group evolved its unique culture and language. Throughout human history the existence of special and separate cultures in physically distant regions has deepened language gaps.

However, with the amazing advances made in the fields of science and technology, the world is rapidly becoming one great village and the call for a genuinely universal language which is fair and easy for everyone has become self-evident. Many pioneers have attempted to create universal languages; unfortunately, their efforts 
have not been successful. The main reason for their failures seems to have been the imperfect method of implementation. For example, grammar relying heavily on inflections has been complicated. Also, their limited vocabularies consisted of words mostly drawn from Eastern European countries have been a major obstacle to their being accepted as universal languages.

In recent years, nations have been getting closer and closer and worldwide issues such as pollution, deterrence of nuclear warfare, and space development have become more than ever pressing to the earth's inhabitants. As a result, the hindrances that foreign languages pose are more keenly felt, and the linguistic variety of the present world is now becoming an increasing burden on international communication. Translations and interpretations help reduce such linguistic barriers. Indeed, international organizations such as the United Nations and the World Trade Organization spend 7.5 percent and 16.6 percent respectively of their total budgets on translations and interpretations. Nevertheless, nobody wants one nation's language to be used as a universal one since it automaticaly delineates first and second class citizens along linguistic lines.

Despite the long history in the quest for a universal language, the aspiration for a single linguistic medium for international communication has not been fulfilled. It has already been discussed that the use of a single natural language as a universal one has its drawbacks; consequently, the world is in great need for a surely artificial language. An international language is a common resource for mankind to promote world peace; its development will prove to be one of the most fruitful global investments. The first step in the creation of an artificial universal language is to draw upon as many strengths of natural languages as possible by selecting words that are most frequently used in our daily lives. Then, the use of this universal language will lead to a broader level of human thought.

Over 80 percent of English words are borrowed; Japanese has borrowed 17 percent of its total vocabulary originated from Western languages for the last 150 years. Before that, Japanese borrowed lots of words from Korean and Chinese, which suggests that most Japanese words are borrowed ones. As human civilization has developed through integration, so can it further develop through a 
unified language. A truly universal language equipped with enriched vocabulary, regular grammar, and simple structure will expand the common intellectual property of mankind. There may come a time when we have only two languages to learn - our mother tongue and the universal language - and live in a unified global nation without any linguistic discriminations or national conflicts.

\section{Principles in the Development of "Unish"}

"Unish", which represents a universal language, is an efficient composition of 16 languages: 13 natural languages spoken by a population more than 70 million people, the root of European languages, Greek and Latin, and the most prominent international language, Esperanto ${ }^{1)}$ ". From those languages, Unish has selected only the words that are short and easy to comprehend and pronounce. English accounts for 85 percent as a result of the fact that English has more borrowed words than any other language. European languages such as Spanish, Italian, and German account for 50-60 percent. Among oriental languages, Chinese, Korean, Japanese, and Hindi account for 5-15 percent of Unish ${ }^{2)}$. This clearly illustrates that almost every primary language is included in it; therefore, it can be quite naturally accepted as a universal language.

Unish is composed of the words that are most widely used among various natural languages. The first guiding principle in the development of Unish is commonness. Most selected Unish words are the ones commonly used in several other languages, or that have been officially used on a worldwide scale and, in consequence, have already become familiar to the global citizens (Chung 1999).

1) We select 13 representative languages for major language families, which happen to have more than 70 million people.

2) The reason why local figure of percentage in origin exceeds 100 is due to the fact that a considerable amount of Unish words has overlapping common roots. 
The second principle is shortness of vocabulary. Unish seeks to create a concise vocabulary with special focus on the simply-spelled words among the vocabularies of similar origin. Moreover, when even the stem of a word sufficiently conveys the meaning, the rest of the word is omitted (i.e. mathmatics $\rightarrow$ math).

The third is diversity. Words have been chosen from as many various languages as possible to expand the degree of familiarity and drawn from a wide range of nations (i.e. path $\rightarrow$ gil, tree $\rightarrow$ namu [Korean]). Consequently, Unish words are usually shorter than those of any other natural languages. This fosters the efficiency of Unish in the age of the Internet.

The fourth is distinctiveness. Unish prefers short words; in the case of a simple word possibly being confused with other words in their pronunciations, such a word has been excluded.

The fifth goal is simplicity. Unish has a structure of CVCV resulting in an easy pronunciation ${ }^{3)}$.

The sixth is cultural association. The origin of words has been respected in Unish by selecting vocabulary that has the closest affinity with other cultures (i.e. tea $\rightarrow$ ch $a$ [Korean]).

Compounding is the final principle adopted in the development of Unish. Unish has created some new words through composition (i.e. dictionary $\rightarrow$ motbuk: mot $=$ word, $b u k=b o o k$ ). Consequent ly, Unish's vocabulary can be expanded without difficulty. Unish has drastically transformed existing words in such a way that everyone can learn it easily.

Based on the aforementioned guidelines, Unish has created words according to the following criteria: First, Unish words avoid unnecessary repetition of consonants (i.e. bell $\rightarrow$ bel).

Second, vowels are made as simple as possible and silent letters at the end of a word are omitted (i.e. guest $\rightarrow$ gest ; sure $\rightarrow$ sur).

Third, when the last consonant has a nasal or fluid sound in CVCV structure, the vowel is omitted (i.e. even $\rightarrow e v n$ ).

Last, words must be simple. When everyone knows how to pronounce a certain word and there is an advantage in shortening it,

3) Here, C stands for a consonant, and V stands for a vowel. 
its spellings can be changed or abbreviated for the convenience of its pronunciation (i.e. business $\rightarrow b i z$; advertise $\rightarrow a d$ ).

To date, Unish has a vocabulary of some 4,000 words through careful word selection and spelling transformation. It aims to enlarge the intellectual horizon of humanity by encompassing identifiable words from every major language of the world. Unish focuses on the primary languages of the world and starts from the words that are most frequently used in our daily lives. A welldirected balancing of languages with an abundant stock of common words and those more limited in usage will enrich the Unish vocabulary, so that people all the world over should be able to enjoy a broader and richer level of thought through the use of this common universal language.

Each language has evolved separately in its own unique surroundings; thus, in some areas it exhibits a higher level of sophistication compared to others. For example, English is the ideal choice in the areas of computers and aeronautical engineering; while Latin and Greek are absolutely the more superior languages in philosophy, medical science, and compound words. Similarly, French is the ideal language for fine arts; German and Italian are the appropriate choices for music. As a result, by systematically and logically combining the strengths of these various languages, we can raise the level of human awareness to new heights and embark on a whole new chapter in the history of mankind.

\section{Dissemination of "Unish"}

The adoption of Unish, a newly born universal language, requires the involvement of many global citizens; the worldwide use of the language cannot be realized without their assistance. In this respect, we can turn to history and learn from the historical precedent of Hangul, the Korean alphabet. While Hangul was first created in 1446 , its widespread dissemination was disrupted due to the chaotic domestic situation following the usurpation of the crown by King Sejong of the Chosun Dynasty. The alphabet barely survived among 
women and peasant classes; it was not until 1910 after the fall of the Chosun Dynasty that Hangul was revived and widely used. Over a period of approximately forty years, the use of the alphabet spread rapidly across the Korean peninsula. By the time of the Korean liberation from Japanese occupation, Hangul was firmly established as the national alphabet. This one example teaches us that any language and alphabet capable of satisfying the needs of the populace can be revived even after being virtually dormant for 500 long years. In spite of its unfamiliar method of marking sounds, Hangul was easily acquired owing to its regular pronunciation, even by the less advantaged people who had been deprived of educational opportunities.

As a first step, we plan to disseminate Unish through the Internet into Korea, China, and Japan (Cumming 1995). The population of the three countries is roughly 1.6 billion accounting for $1 / 4$ of the world's population. Culturally, the three nations have a multitude of things in common. In spite of such advantages in national exchanges, the three have had to communicate in a fourth language - English, because they were ignorant of each other's language. As a result, communication among the youth of the three countries with Unish will improve their exchanges. Initially, the basic 4,000 words will be disseminated through various Internet homepages receiving at the same time the responses and opinions of many and sundry people.

Secondly, Unish will be very useful in the area of travel. With the marvelous advances in transportation technology and the rapid rise of income, the annual figure for international tourists may well be currently over 500 million. They are most affected by the lack of a universal language. Their inability to communicate in a foreign tongue remains one of the stumbling blocks in international travel. Indeed, given the vast increase in the volume of international travel the tourists' language problems, when confronting local language obstacles, are growing. The international airports of today resemble art galleries with pictograms scattered all over. These language barriers can be overcome by the use of Unish.

Lastly, translation and publication will facilitate the global spread of Unish. The common heritage of the world including classics, 
poems, popular songs, Bible, etc., can be translated in Unish and distributed to every comer of the planet. A Unish dictionary on the Internet will be a useful guide for its learners. The key step is to edit a dictionary in the three national alphabets of Korea, China, and Japan. Furthermore, people in those countries will have an easy access by reading books translated into Unish on their common history and culture. For children, popular songs in Unish are a good entrance to the acquisition of this international language.

\section{Conclusion}

Unish embraces the advantages of natural languages, particularly those of English. Even though English lost many of its inflections during the French rule of England, it is still difficult for foreign learners to learn due to its irregularity of pronunciation and grammar. On the other hand, Unish has a simple and regular grammar and is pronounced in the way that it is written.

Anglo-Americans are strongly prejudiced to claim that English is the only candidate for a universal language. It, however, is hardly imaginable that countries like France, Germany, Russia, and China will accept English as an international language and tolerate their position as second class citizens. Now is the time, therefore, for us to create a universal language as a common property for mankind. English has developed itself with its diverse regional characteristics. What draws our particular attention here is "Pidgin English" which was used in colonies of England and America in the region of the South Pacific. Pidgin developed in a situation where laborers from various ethnic groups had no common language of communication. It was like an imitation of English with 1,500 basic words and a word order of $\mathrm{SVO}^{4}$. Furthermore, it has no lenses, no inflections, and no gender distinctions. In fact, Pidgin English is not merely a random mixture of languages, but what has emerged out of human instincts and the need for communication, which clearly suggests

4) In this paper, $\mathrm{S}$ is an abbreviation used for a subject, $\mathrm{V}$ for a verb, and $\mathrm{O}$ for an object. 
something for the creation of a common language for international communication.

Humans think only in language. Then, Unish as an excellent combination of primary natural languages will expand the intellectual horizon of global citizens and provide them with the means to make the global village a reality.

Unish will be more easily disseminated by a citizens' campaign on a long term basis through the Internet and traveling than by a single national campaign on a short term basis, just as Christianity and other belief systems have spread all over the world by a countless number of missionaries over an extended period. The necessity of that campaign is more keenly felt in medium-sized countries like Korea than in those with strong national power including English-speaking nations. When this lengthy and ambitious movement promoting Unish comes to fruition Pax Lingua, the ancient and ongoing quest of mankind will be surely realized. 


\section{References}

Chung, Young-hee. 1999. Borrowing as a Strategy for a Universal Language. Journal of Sejong Language 5: 27-36.

Cumming, John. 1995. The Internet and the English Language. English Today 11: 3-8.

Comrie, Bernard. 1999. Natural and Artificial International Languages: a Typologist's Assessment. Journal of Universal Language I:33-55.

Diamond, Jared. 1999. Sejong's Achievement as viewed by an American. Journal of Universal Language I: 11-19.

Glossop, Ronald. 1988. Language Policy. In Klaus Schubert. Interlinguistics: Aspects of the Science of Planned Language. Berlin: Mouton.

Large, Andrew. 1985. The Artificial Language Movement. Oxford: Blackwell. 1996. The Prospects for an International Language.

Journal of Universal Language 1: 20-34.

Suzanne, Romaine. 1998. Pigin and Creole Linguistics. London: Longman. 